\title{
COLEÇÃO NÁSSARO NASSER \\ A Cerâmica Decorada no Acervo Arqueológico do Museu Câmara Cascudo, UFRN
}

\section{NASSER NASSER COLLECTION \\ The Decorated Pottery of the Collection of Archeology of the Câmara Cascudo Museum, UFRN}

\author{
Luciano de Souza Silva ${ }^{1}$ \\ lucianoarque@yahoo.com.br \\ Moysés M. de Siqueira Neto ${ }^{1}$ \\ moyses_neto@yahoo.com.br \\ Thaise G. Rodrigues ${ }^{2}$ \\ taisegab@hotmail.com \\ Carina Peixoto ${ }^{2}$ \\ carinapeixoto442@gmail.com
} Gildo Júnior dos Santos ${ }^{1}$

\section{RESUMO}

Esse trabalho apresenta as características e a variabilidade decorativa da cerâmica arqueológica pertencente à Coleção Nássaro Nasser. A coleção foi formada a partir da atividade científica do arqueólogo Nássaro de Souza Násser, no Instituto de Antropologia, atualmente Museu Câmara Cascudo/UFRN, em parceria com o Smithsonian Institution e o Programa Nacional de Pesquisas Arqueológicas/PRONAPA, nas décadas de 1960 e 1970. Para isso, foram realizadas revisão bibliográfica; arrolamento do material cerâmico; formulação de fichas para coletas de informações; registro fotográfico; análise do material; catalogação das informações utilizando fichas; e identificação da decoração de cada recipiente e fragmento cerâmico com decalque virtual das superfícies internas e externas por meio de fotografias.

Palavras-Chaves: Arqueologia, Acervo, Cerâmica e Decoração.

\footnotetext{
${ }^{1}$ Museu Câmara Cascudo, UFRN.

2 Discente, Departamento de História, UFRN.
} 


\begin{abstract}
This work presents the characteristics and the decorative variability of the archaeological pottery belonging to the Nássaro Nasser Collection. The collection was formed from the scientific activity of the archaeologist Nássaro de Souza Násser, at the Instituto de Antropologia (Institute of Anthropology), currently the Museu Câmara Câmara Cascudo / UFRN, in partnership with the Smithsonian Institution and the Programa Nacional de Pesquisas Arqueológicas/PRONAPA (National Archaeological Research Program) in the 1960s and 1970s. For this, were performed a bibliographic review; list of the pottery material; formulation of records to collect information; photographic register; material analysis; cataloging information using records; and identification of the decoration of each pottery and pottery fragment with virtual decal of the internal and external surfaces using photographs.
\end{abstract}

Keywords: Archeology, Collection, Pottery and Decoration.

\title{
CONTEXTO DAS CERÂMICAS DO MUSEU CÂMARA CASCUDO
}

Mais de 60 anos das pesquisas científicas sobre arqueologia resultaram em

avanços no conhecimento sobre a variabilidade da cerâmica pré-colombiana no Brasil. As análises permitiram a formação de um quadro geral para o entendimento das variedades nos modos de produção, recursos, decoração, contextos e suas conexões com os modos de viver, assentamentos, densidade populacional, entre outras informações sobre as sociedades do passado.

Parte do acervo arqueológico coletado ao longo do desenvolvimento das pesquisas ocupa atualmente as reservas técnicas de museus e outras instituições de pesquisa brasileiras e internacionais. Novos questionamentos científicos, suas teorias e técnicas, bem como o acesso às novas tecnologias propõem outros desafios que muitas vezes - se distanciam dos objetivos das pesquisas que geraram o acervo. 
O Museu Câmara Cascudo da Universidade Federal do Rio Grande do Norte (MCC/UFRN) reúne cerca de 150 mil vestígios arqueológicos coletados ao longo de sua história. Dentre eles, destaca-se o conjunto cerâmico reunido na Coleção Nássaro Nasser, oriundo das atividades do arqueólogo Nássaro de Souza Násser, no Instituto de Antropologia (IA) em parceria com o Smithsonian Institution e o Programa Nacional de Pesquisas Arqueológicas (PRONAPA), nas décadas de 1960 e 1970.

Após as pesquisas no contexto do PRONAPA, a coleção permaneceu depositada no MCC/UFRN em condições mínimas de conservação e poucas ações para sua documentação, pesquisa e comunicação. Esse trabalho retoma as análises arqueológicas após mais de 40 anos e apresenta as particularidades decorativas nas cerâmicas arqueológicas da Coleção Nássaro Násser. São consideradas as representações decorativas compreendidas como ícones desenhados/projetados (design) que podem representar diferentes temas, funcionando como forma de linguagem, geralmente carregados de simbolismos e significados. Sem adentrar no campo interpretativo, buscamos apresentar as características e a variabilidade decorativa da cerâmica arqueológica pertencente a Coleção Nássaro Nasser do acervo do Setor de Arqueologia do Museu Câmara Cascudo-MCC/UFRN.

\section{A COLEÇÃO NÁSSARO NASSER NO MCC/UFRN}

O Museu Câmara Cascudo da Universidade Federal do Rio Grande do Norte foi criado em 1973 para salvaguardar as primeiras coleções originadas nas atividades 
de coleta das pesquisas do Instituto de Antropologia da Universidade do Rio Grande do Norte - IA/URGN (1960-1973) ${ }^{3}$. Na sua formação inicial, o Instituto de Antropologia tinha atividades de Antropologia Física, com pesquisas de José Nunes Cabral de Carvalho sobre sambaquis; Etnografia Geral com pesquisa sobre ecologia noite-rio-grandense de Luiz da Câmara Cascudo; uma sessão de Cultura Popular com Veríssimo Pinheiro de Melo; e Genética, com Professor Monsenhor Nivaldo Monte (SANTOS, 2010).

Como demonstrou a documentação de Veríssimo de Melo, em 1962, o objetivo era de "criar um homem norte-riograndense, síntese de todos os municípios do Estado, inclusive com os recantos mais distantes". Através da atividade científica institucionalizada, buscou-se o processo de trabalho de construção de referências às identidades coletivas regionais, envolta de questões locais, étnicas, sexuais, raciais ou de gênero. Woodward (2009) identifica que tais questões são fundamentais nas classificações que permitem as respostas às questões: quem eu sou? O que eu poderia ser? Quem eu quero ser?" por um conjunto especial de circunstâncias, sentimentos, histórias e experiências.

Desde as primeiras atividades de pesquisa, com a coleta de material pré-colonial para levantamento antropológico da equipe do IA na Serra do Ronco, no

\footnotetext{
${ }^{3} \mathrm{O}$ instituto foi criado em 1960 com o objetivo de promover e divulgar estudos sobre o Rio Grande do Norte em seus diversos aspectos. Em 1961 foi incorporado à Universidade do Rio Grande do Norte (URGN) e, em 1965, passou a se chamar Instituto de Antropologia Câmara Cascudo (IACC). Em 1973, o instituto virou Museu Câmara Cascudo, nome que possui até os dias atuais.
} 
município de São Tomé/RN, os bens arqueológicos foram objeto de coleta, classificação e análise no instituto, o que gerou demanda para criação de um setor próprio para arqueologia. Em 1970, o IA já contava com 8 secções: Antropologia Cultural; Antropologia Biológica; botânica; Genética; Zoologia; Paleontologia; Geologia; e Arqueologia.

O Setor de Arqueologia contou com Nássaro de Souza Nasser como responsável pelas pesquisas na década de 1960 e 1970. O pesquisador nasceu em Macaíba/RN e era graduado em geografia. Em 1963, recebeu uma formação inicial para etnografia, no curso de Introdução à Antropologia com pesquisadores do IA, com as disciplinas de geologia, etnografia, antropologia física e linguística. Após o curso, foi selecionado para fazer parte da equipe de pesquisadores.

Nasser teve influência direta das atividades de cooperação internacional com a Smithsonian Institution (Estudos Arqueológicos das Grandes Bacias fluviais sulamericanas), através do Programa Nacional de Pesquisa Arqueológica, o PRONAPA (MEGGERS, 2007). Em 1964, Nássaro Nasser recebeu treinamento para as pesquisas com material cerâmico pré-colombiano com Betty Jane Meggers e Clifford Evans, do Smithsonian Institution, no Seminário de Ensino e Pesquisa em Sítios Cerâmicos. Com Valetin Calderon aprofundou a experiência na prática de campo e com Mario Simões, do Museu Emilio Goeldi-PA, especificamente nos trabalhos de análise cerâmica (NASSER, 2017). 
As atividades arqueológicas se iniciaram no sítio a céu aberto Aldeia Curimataú, na cidade de Vila Flor/RN. O local foi alvo das escavações sistemáticas para o entendimento dos sítios cerâmicos no processo de migração e modos de vida dos grupos pré-colombianos. Segundo as publicações e informações do próprio Nássaro Nasser, as pesquisas se iniciaram em 1965, com prospecções extensivas que avançaram da bacia do Rio Curimataú também pelos municípios Georgino Avelino até a Serra de São Bento (NASSER, 2017).

Nássaro Nasser desenvolveu três projetos principais no IA-URN: (1) PRONAPA, que investigava uma cronologia relativa para a ocupação pré-europeia; (2) os Estudos de Ecologia Cultural visava uma inter-relação entre as culturas préhistóricas e meio ambiente; e (3) projeto referente a Arte Rupestre no RN, com levantamento de sítios com arte rupestre.

Suas publicações comunicaram os resultados da pesquisa na da bacia do rio Curimataú (NASSER, 1967;1971), Lagoa de Guaraíras no município de George Avelino (NASSER, 1974) e resultados em conjunto dos projetos relativos ao PRONAPA (BROCHADO et al, 1969;1970). Conjuntamente com Elizabeth Cabral, foram documentadas as inscrições rupestres no Rio Grande do Norte (CABRAL \& NASSER, 1983)

Após o retorno do mestrado em antropologia na Bahia, em 1976, quando trabalhou com questões indígenas no submédio do São Francisco (Rodelas/Bahia) 
com os Tuxás, Nássaro encontrou dificuldades de trabalho no IA e resolveu interromper suas pesquisas no campo da arqueologia. Seu trabalho publicado teve importante ressonância no campo arqueológico nacional e internacionalmente.

A coleção atual (menor do que o coletado no período) contem 4.780 peças fragmentadas, ocupando 58 caixas $\left(130 \mathrm{~g} / \mathrm{m}^{2}\right.$ com $\left.35 \times 13 \times 25 \mathrm{~cm}\right)$ na reserva do Setor de Arqueologia do MCC-UFRN.

\section{ATIVIDADES TÉCNICAS}

Os parâmetros metodológicos para o desenvolvimento da pesquisa foram os seguintes: (i) Pesquisa (revisão) bibliográfica de caráter documental, histórico e arqueológico; (ii) Levantamento do material cerâmico disponível no Acervo do Setor de Arqueologia do Museu Câmara Cascudo; (iii) Formulação de fichas para coletas de informações; Levantamento e registro fotográfico da cerâmica do acervo; (iv) Análise do material cerâmico, preenchimento de informações por meio de fichas, e identificação da decoração de cada recipiente e fragmento cerâmico. (iv) Decalque virtual das superfícies internas e externas por meio de fotografias, utilizando os programas Adobe Photoshop e Corel Drawl.

Buscando o ordenamento das informações, foi desenvolvido a sistematização de um Banco de Informações (BINFOR), no programa Excel, permitindo gerenciar as informações gerais e concomitantemente ao inventário específico do acervo. $\mathrm{O}$ BINFOR contém as seguintes categorias: projeto, sítio, código do sítio, código de sítio no MCC, estado, município, localidade, topônimo, fonte d'água, UTM, 
coordenadas geográficas, intervenção de solo, setor, unidade, nível, camada, coleção, código da coleção, modo de aquisição, data de aquisição, id. das peças, outro id. das peças, tipo de material, classificação, quantidade de material (unidade), peso (g), higienização, triado, analisado, restaurado, horizonte cultural, período, cronologia, descrição, estado de conservação, referência bibliográfica, id. imagem, localização da imagem digital no acervo, local de guarda, estante, id. caixa, número de sacos, forma de acondicionamento, id. estante, localização atual, histórico de movimentação da peça e por fim observações.

O Banco de Informações - chamado de BINFOR - serviu para o ordenamento dos componentes de forma qualitativa e quantitativa tendo como base as características dos objetos possibilitando a realização de identificação e classificação dos vestígios. Em relação ao material cerâmico, inicialmente, o processo de identificação dessas peças se dava pela presença ou não de decoração. Realizamos levantamento fotográfico do acervo cerâmico, tanto dos fragmentos, quanto dos recipientes inteiros, as informações e descrições das peças foram registradas por meio de fichas com descritores próprios para coleta de informações de objetos cerâmicos. As imagens digitais (fotos) foram salvaguardadas e organizadas no banco de informações. Algumas imagens foram selecionadas para a execução do decalque virtual, objetivando a identificação da decoração da cerâmica. 
Para o reconhecimento e identificação dos detalhes da composição de cada elemento decorativo, além da utilização das fotografias como complemento e rigor foram utilizados na etapa de análise de laboratório ferramentas de software para o tratamento de imagem.

Nessa fase utilizamos o programa Adobe Photoshop CS2, Movavi Photo Editor 5 e Corel Draw. Os passos fundamentais ocorrem através da correção com realce automático ou manual das cores. Aplicação de efeitos de curvas de cores para dar destaque às pinturas e realização da elaboração do decalque virtual mediante ferramenta de seleção de cor e cobertura continua dos motivos representados. Estes procedimentos garantem as características dos motivos iconográficos de cada objeto.

\section{RESULTADOS}

As 4.780 peças foram realizadas o registro fotográfico, e os 894 materiais decorados foram catalogados e realizado a identificação da decoração. O material cerâmico fragmentado foi classificado em 6 categorias: Borda Decorada (BD), Borda Sem Decoração (BSD), Parede Decorada (PD), Parede Sem Decoração (PSD), Fundo Decorado (FD) e Fundo Sem Decoração (FSD). Aparecendo objetos, como aplique, cachimbo, pedestal e apêndice. 


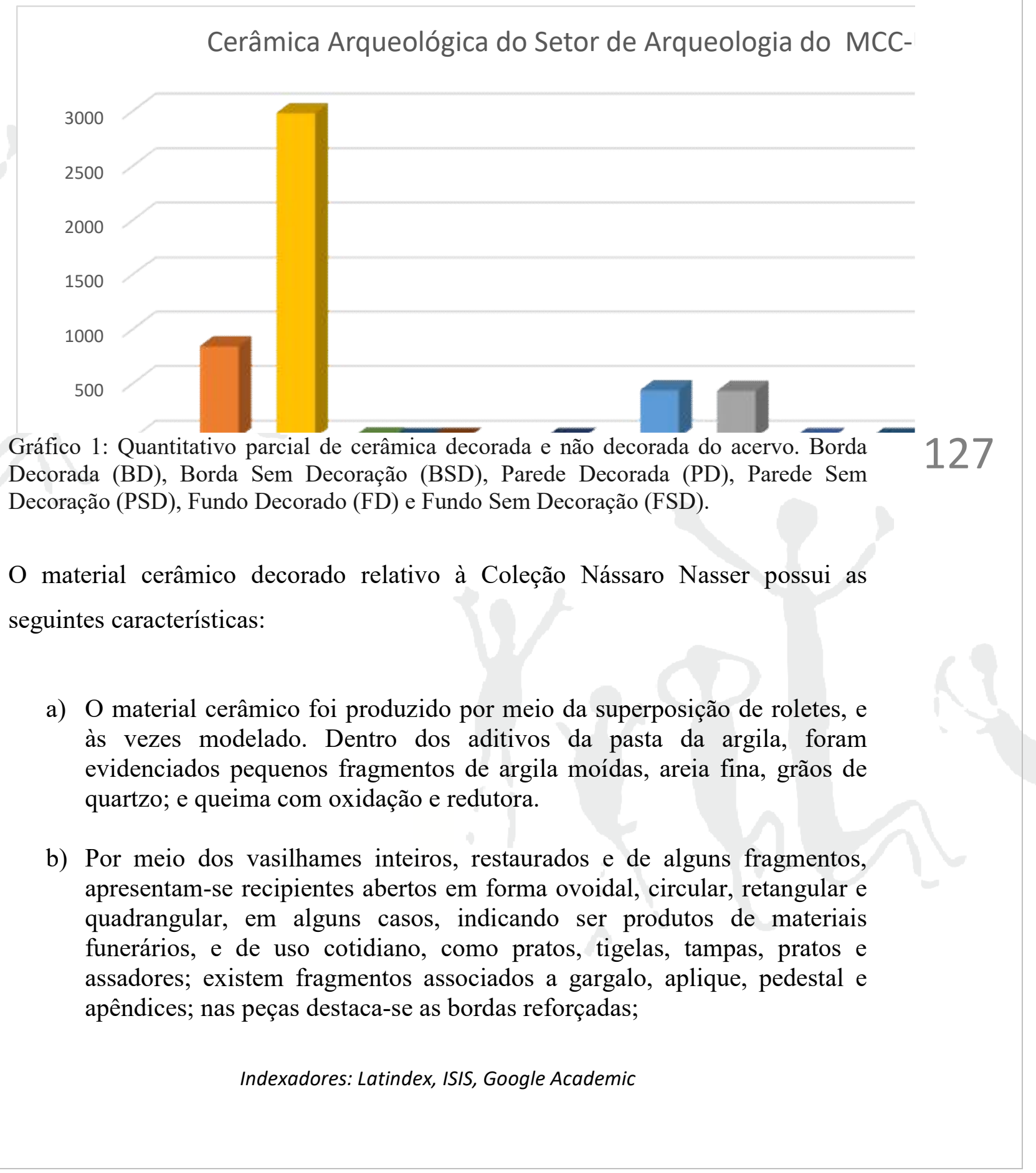


c) Os recipientes são grandes, médios e pequenos, a parte superior da região das bocas variam de constrita/contraída à ampliada, tem contorno simples e o bojo é largueado, e na parte da base, geralmente arredondada.

d) O tratamento de superfície é corrugado, escovado, alisado, destacando os acabamentos plásticos e os pintados;

e) A decoração plástica possui sulcos ou canais em baixo relevo, linhas incisas, e em algumas peças, existem decorações ponteadas;

f) Os motivos pintados nos vasilhames inteiros ou remontados, observa-se nas paredes que os desenhos são distribuídos em zonas, possuindo particularidades no bojo e em direção a área da borda. A decoração geralmente é policrômica na face interna, marcada pela presença desenhos lineares sobre o fundo engobado.

g) A composição colorimétrica é observada pigmentos monocromáticos e policromáticos. As cores são: vermelho, vermelho escuro, vermelho claro, vinho, laranja, amarelo, cinza, preto, branco e o branco em diferentes tonalidades.

h) A decoração pintada ocorre sob forma de desenhos geométricos, indicando representações complexas do mundo ideativo dos autores, eles cobrem a superfície em linhas finas, tarjas continuas seguindo o formato do recipiente, sendo em vermelho ou castanho, geralmente sobre o engobo branco com leve tom amarelado. O vermelho e o alaranjado, ás vezes aparecem como engobo, indicando um tipo de banho realizado sobre a superfície do material cerâmico. 
i) A coloração vermelho existe traços largos do tipo tarja, e é aproveitado para colorir longas faixas que destacam os relevos e as partes do recipiente, localizados, preferencialmente, no bojo ou borda dos recipientes;

j) As decorações representadas em traços finos, são geralmente retas, curvilíneas, aparecendo na horizontal, vertical, diagonal ou oblíqua. Podem ser representadas isoladas ou arranjadas entre si através de pontos formando padrões em linhas paralelas, oblíquas, ziguezagues, quadriculadas, triangulares, circulares, volutas, retangulares.
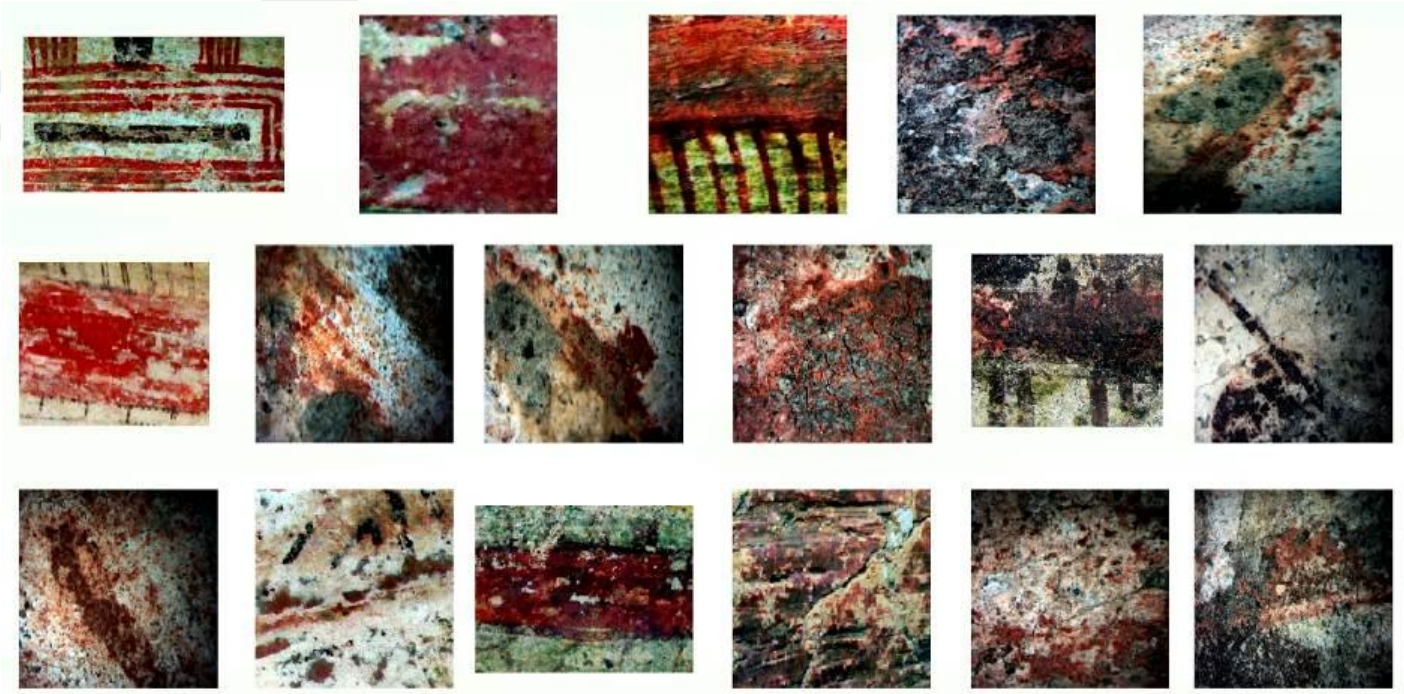

Figura 1: Cores da superficie da cerâmica da Coleção Nássaro Nasser, Setor de Arqueologia do MCC-UFRN. 

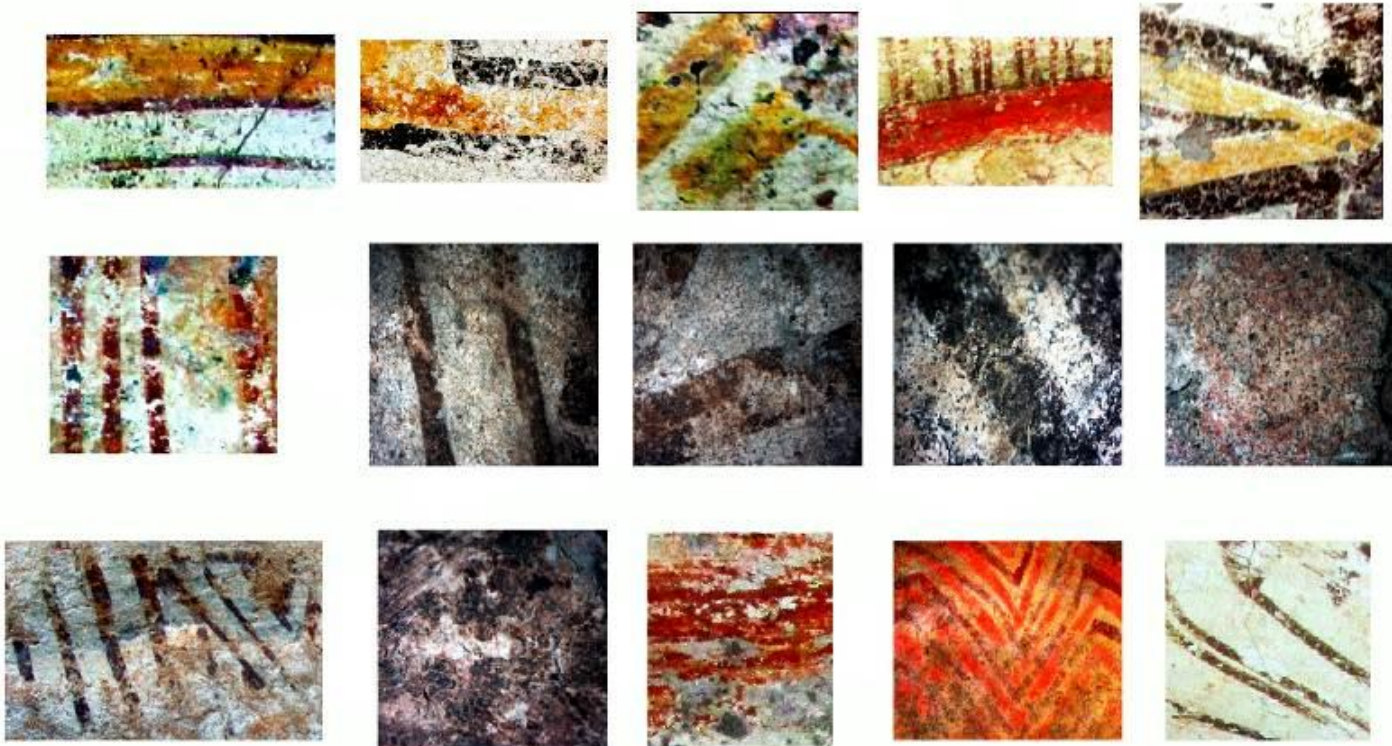

Figura 2: Cores da superficie da cerâmica da Coleção Nássaro Nasser, Setor de Arqueologia do MCC-UFRN.
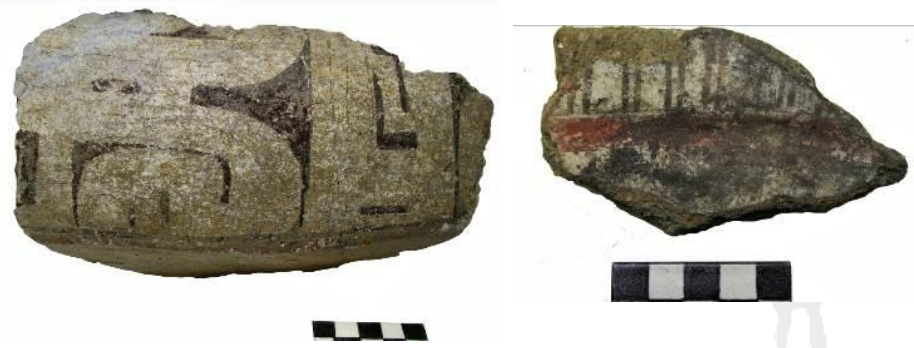

Figura 4: Fragmentos cerâmicos decorados. O artefato da esquerda, possui decoração pintado na parte externa; e o recipiente da direita, possui decoração pintada na parte interna.

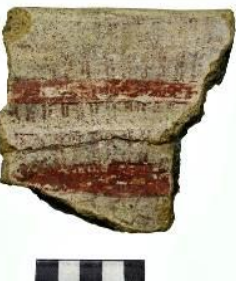

Figura 5: Fragmentos cerâmicos decorados na parte interna.

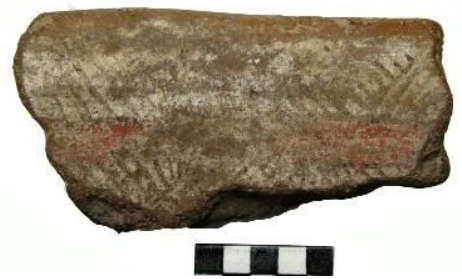

Indexadores: Latindex, ISIS, Google Academic 

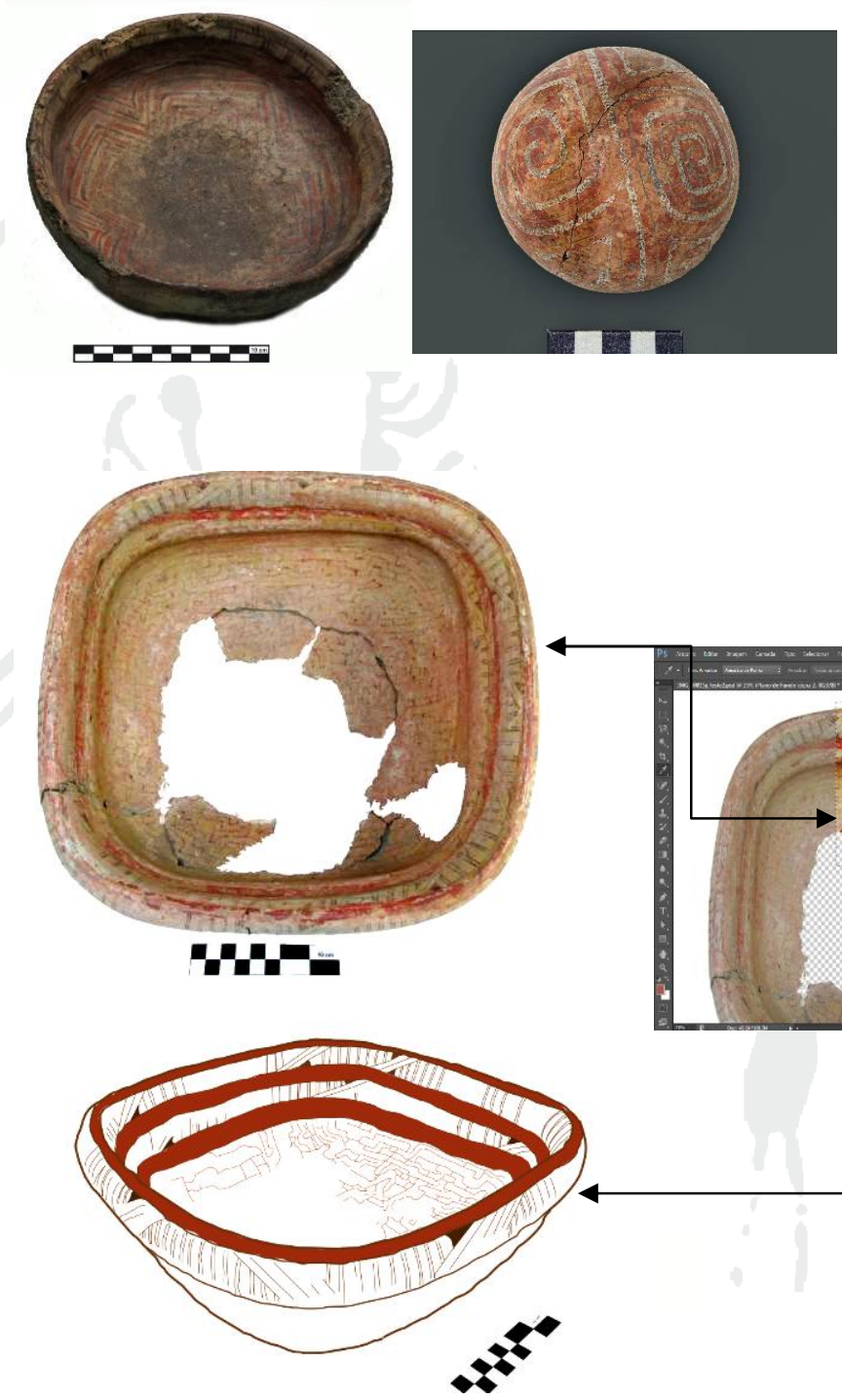

Figura 4: Imagem do Recipiente Cerâmico do Acervo do Setor de Arqueologia. Detalhe: Identificação da decoração.
Figura 3: Recipientes cerâmicos decorados. O artefato da esquerda, possui decoração pintada na parte interna; e o recipiente da direita, possui decoração plástica na parte externa. 

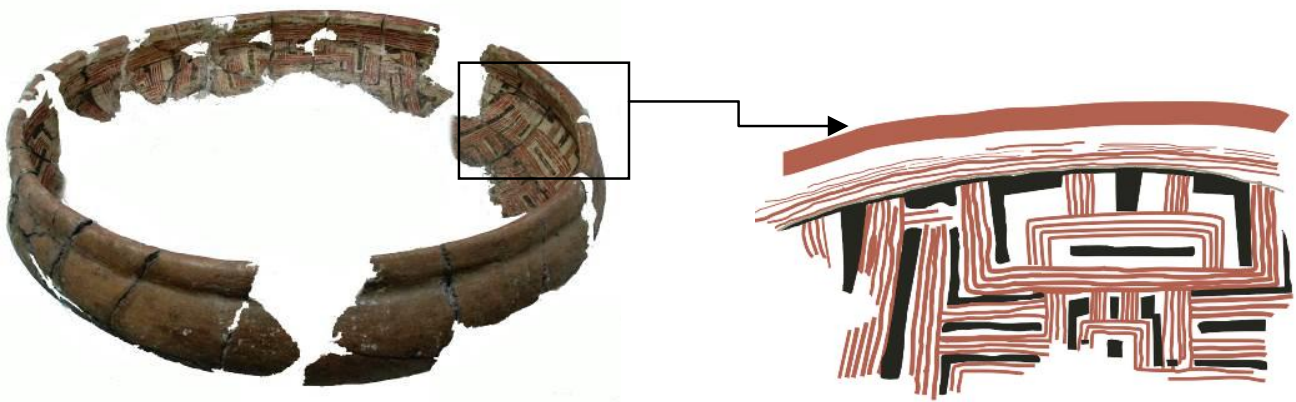

Figura 5: Imagem do Recipiente Cerâmico do Acervo do Setor de Arqueologia MCC/UFRN. Detalhe: Identificação da decoração.

\section{CONSIDERAÇÕES FINAIS}

Os artefatos/objetos arqueológicos/etnográficos de valor histórico e cultural são registros das escolhas e de variedades estéticas que possibilitam conhecer um traço da cultura das sociedades ameríndias no presente e no passado.

A recorrência de unidades de desenhos graficamente semelhantes e motivos de diferentes complexidades pode levantar a hipótese lógica que os mesmos possuíam o objetivo de expressar determinados conteúdos semânticos.

Os elementos decorativos da Coleção Nássaro Nasser apresentam uma diversidade decorativa, identificando certos padrões e especificidades, podendo fazer parte de um meio ativo de comunicação e, onde os indivíduos ou grupos negociam, definem, afirmam, recusam ou estabelecem relações sociais -, e não são só apenas com um produto passivo. 
A decoração apresenta simetria nos volumes, sendo pintada e com características linear e pontilhada, na cor vermelho claro, vermelho escuro, laranja, vinho, marrom ou preta, e geralmente com engobo branco no acabamento de superfície. As representações são geometrizadas, com composição organizada em alinhamentos ao longo de eixos paralelos; disposição espiralada ou concêntrica; áreas ocupadas por feixes de linhas paralelas na vertical e horizontal.

Possuem linhas paralelas, retas ou arranjadas ortogonalmente, localizando na parte interna e externa dos recipientes parcialmente inteiros, subindo até meia altura das paredes, decorado com linhas curvas vermelhas (claras e escuras) e/ou pretas muito finas, e com pontos escuros destinados a reforçar as linhas mestras, dando contrastes nas superfícies.

A partir da identificação da variabilidade, dos motivos decorativos representados na cerâmica, pode-se colaborar com as hipóteses das relações de sociedades integradas em redes de trocas, que, talvez, possam pertencer a especificidades culturais e de relações sociais, sendo evidenciado em grande escala produtiva no registro arqueológico ameríndio há \pm 4 mil anos B.P. O material cerâmico destina aos contextos ecológicos e culturais, atendendo as necessidade dos grupos, representando especificidades decorativas. 


\section{BIBLIOGRAFIA}

BROCHADO, José Proenza; CALDERON, Valentin; CHMYZ Igor; DIAS, Ondemar F., EVANS Clifford; MARANCA Sílvia; MEGGERS, Betty J.; MILLER, Eurico Th.; NASSER, Nássaro A.; PEROTA, Celso; PIAZZA, Walter F.; RAUTH, José Wilson; SIMÕES, Mário F. Arqueologia brasileira em 1968: um relatório preliminar sobre o Programa Nacional de Pesquisas Arqueológicas. Belém, Publicações Avulsas, n. 12, p. 140.1969. Museu Paraense Emílio Goeldi, Publicações Avulsas 12.

BROCHADO, José Proenza; CALDERON, Valentin; CHMYZ Igor, DIAS, Ondemar F.; EVANS Clifford; MARANCA Sílvia; MEGGERS, Betty J.; MILLER, Eurico Th.; NASSER, Nássaro A.; PEROTA, Celso; PIAZZA, Arqueologia, Número especial, Curitiba, v. 4, p. 31-56, 200753 A contribuição do Brasil à interpretação da linguagem da cerâmica Walter F.; RAUTH, José Wilson; SIMÕES, Mário F. Brazilian archaeology in 1968: an interim report on the National Program of Archaeological Research. American Antiquity, v. 35, p. 1-23. 1970.

CABRAL, Elizabeth Mafra; NASSER, Nássaro A. Souza - Informação sobre inscrições rupestres no Rio Grande do Norte. Natal: UFRN, Série B, n. 384. (Coleção Mossoroense) 1983. (BCZM - UFRN).

NASSER, Nássaro. Notas preliminares sobre a arqueologia do sistema CurimataúCunhaú. Publicações Avulsas do Museu Goeldi. Programa Nacional de Pesquisas Arqueológicas: resultados preliminares do primeiro ano 1965 - 1966. n. 6. Belém: Museu Paraense Emílio Goeldi, 1967.

. Considerações preliminares sobre a arqueologia. Publicações Avulsas do Museu Goeldi. Programa Nacional de Pesquisas Arqueológicas: resultados preliminares do quarto ano 1968 - 1969. n. 15. Belém: Museu Paraense Emílio Goeldi, 1971.

Nova contribuição à arqueologia do Rio Grande do Norte. In: Publicações Avulsas do Museu Goeldi. Programa Nacional de Pesquisas Arqueológicas: resultados preliminares do quinto ano 1969 - 1970. n. 26. Belém: Museu Paraense Emílio Goeldi, 1974. 
. Entrevista I. [set. 2017]. Entrevistador: Carina Peixoto, Luciano Souza e Moysés Siqueira. Natal, 2017. 1 arquivo .mts (80 min.).

WOODWARD, K. Identidade e diferença: uma introdução teórica e conceitual. In:SILVA. Tomas Tadeu da. (Org). Identidade e diferença: a perspectiva dos estudos culturais. Petrópolis, RJ: Vozes, 2009. p.7-72. 